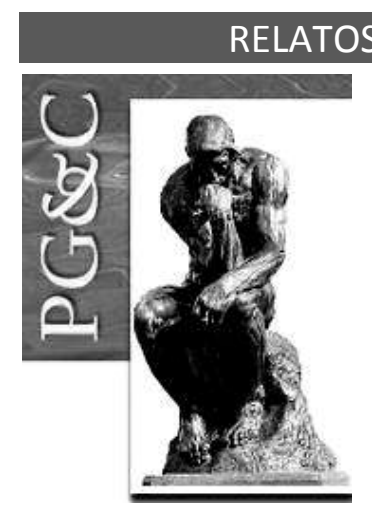

\title{
PANORAMA DA TRANSPARÊNCIA ATIVA NOS PORTAIS ELETRÔNICOS DAS INSTITUIÇÕES PÚBLICAS DE ENSINO SUPERIOR DA REDE FEDERAL NA PARAÍBA
}

\author{
Victor Hugo Sousa de Oliveira \\ Mestre em Gestão de Organizações Aprendentes pela Universidade \\ Federal da Paraíba, Brasil. Secretário Executivo da Universidade Federal da \\ Paraíba, Brasil. \\ E-mail: vichugo.jp@gmail.com \\ Bernardina Maria Juvenal Freire de Oliveira \\ Doutora em Letras pela Universidade Federal da Paraíba. Professora da \\ Universidade Federal da Paraíba, Brasil. \\ E-mail: bernardinafreire@gmail.com \\ José Washington de Morais Medeiros \\ Doutor em Educação pela Universidade Federal da Paraíba. Professor do \\ Instituto Federal da Paraíba, Brasil. \\ E-mail: washimed@yahoo.com.br
}

\begin{abstract}
Resumo
$\mathrm{Na}$ conjuntura mundial contemporânea da sociedade conectada em rede, a disponibilidade e importância da informação em formato digital em toda a atividade humana foi alçada a patamares mais elevados, sobretudo para o exercício da cidadania. O presente artigo tem como objetivo analisar o cumprimento e adequação das três instituições federais de ensino superior (IFES) no Estado da Paraíba à divulgação de informações mínimas obrigatórias (transparência ativa) determinada pela Lei de Acesso à Informação (LAI), e seu decreto regulamentador, à luz dos avanços tecnológicos da sociedade da informação. Partindo da Declaração Universal dos Direitos Humanos da Organização das Nações Unidas, levanta outros instrumentos internacionais que versam sobre o tema e influenciaram a criação das normas brasileiras. Além disso, debate a cidadania digital favorecida pela transparência pública online. Metodologicamente utiliza referencial teórico e análise documental da legislação específica para interpretar os dados obtidos por meio do instrumento de pesquisa elaborado: quadros preenchidos com os pontos de transparência ativa verificáveis nos portais eletrônicos das instituições pesquisadas. Conclui que as três instituições pesquisadas procuram se adequar à legislação pertinente, ainda que a maneira de entrega das informações apresente variações de instituição para instituição.
\end{abstract}

Palavras-chave: Transparência ativa. Cidadania digital. Acesso à informação.

\section{PANORAMA OF ACTIVE TRANSPARENCY IN THE WEBSITES OF PUBLIC HIGHER EDUCATION INSTITUTIONS OF THE FEDERAL NETWORK IN PARAÍBA}

\begin{abstract}
In the contemporary world context of the networked society, the availability and importance of information in digital format in all human activity has been raised to higher levels, especially for the exercise of citizenship. The main objective of this article is to analyze the compliance and adequacy of the three federal higher education institutions in the State of Paraiba to the disclosure of minimum mandatory information (active transparency) determined by the Brazilian Access to Information Law (LAI), and its decree in the light of technological advances in the information society. Starting with the
\end{abstract}

Perspectivas em Gestão \& Conhecimento, João Pessoa, v. 10, n. 3, p. 262-279, set./dez. 2020. DOI: https://dx.doi.org/10.21714/ufpb.2236-417X.2020v10n3.55622

http://periodicos.ufpb.br/ojs2/index.php/pgc. ISSN: 2236-417X. Publicação sob Licença (cc) EY-NC-ND 
Universal Declaration of Human Rights of the United Nations, we raised other international instruments that deal with the theme and influenced the creation of Brazilian legislation. In addition, we discussed digital citizenship favored by online public transparency. Methodologically, we used this theoretical framework and document analysis of specific legislation to interpret the data obtained in the research instrument created: tables to be filled in with the points of active transparency verifiable in the electronic websites of the researched institutions. We conclude that, as the obtained data demonstrate, the three researched institutions try to adapt to the pertinent legislation, even though the way in which the information is delivered varies from institution to institution.

Keywords: Active transparency. Digital citizenship. Access to information.

\section{INTRODUÇÃO}

Este artigo resulta da pesquisa intitulada $D a$ Aprendizagem Virtual às Práticas Cotidianas: concepção dos servidores sobre a aplicação da Lei de Acesso à Informação na UFPB desenvolvida junto ao Programa de Pós-Graduação em Gestão de Organizações Aprendentes da Universidade Federal da Paraíba (UFPB).

Neste artigo, procuramos aprofundar o estudo com referência ao aspecto mais visível da transparência à luz da legislação brasileira, a transparência ativa, pois esta elenca as informações essenciais que devem ser disponibilizadas pelos órgãos do poder público, sem prejuízo a outras informações públicas, os quais detêm informações relevantes para possibilitar à população o exercício da cidadania no contexto da sociedade conectada à rede mundial de computadores.

Os resultados preliminares deste estudo suscitaram questões quanto à discrepância da transparência ativa da instituição e a percepção de transparência geral pelos servidores da instituição.

\subsection{Demandando informação pública na Era da Sociedade em Rede}

Nosso ponto de partida é a cibercultura, definida por Lévy (2000, p. 17) como um conjunto de técnicas materiais e intelectuais, de práticas, de atitudes, de modos de pensamento e de valores que se desenvolvem com o crescimento do ciberespaço, ou a rede mundial interconectada onde interagem as pessoas em meio às informações numa infraestrutura de comunicação digital. Hoje, ela espelha a face da integração global onde, cada vez mais, relações e trocas em escala global acontecem na virtualidade.

Com o crescimento do ciberespaço, houve a intensificação da diminuição do distanciamento entre povos, culturas e países. Isso só se torna possível pela evolução de tecnologias da informatização como consequência do desenvolvimento dos computadores pessoais e, mais recentemente, de máquinas de comunicação digital (smartphones, internet etc). Este fato é mais uma etapa do processo já conhecido da humanidade: a globalização.

Nesta grande aldeia global (IANNI, 2001), a virtualização das atividades humanas segue a lógica mercadológica, onde os cidadãos passam a consumidores também de informações diversas. A aldeia global se desenvolve e avança no mundo virtual, digitalizado e instantâneo, e as necessidades passam a um patamar diferenciado.

A partir desta relação entre mercado e consumo de informação na sociedade da informação, os governos também estão compelidos a disponibilizar informações públicas nos mesmos moldes de celeridade em que o mercado opera, devendo assim fazer um esforço para responder a este desafio em vistas de seu poder regulamentador.

Diante disto, intensifica-se o imperativo para a transparência pública das atividades da administração pública, em decorrência da consolidação dos direitos fundamentais, que foram

Perspectivas em Gestão \& Conhecimento, João Pessoa, v. 10, n. 3, p. 262-279, set./dez. 2020. 
mais intensamente debatidos desde o pós-guerra, com a Declaração Universal dos Direitos Humanos (DUDH) em 1948. Como resultado, este pacto mundial provocou, mesmo que anos depois, em algumas partes do mundo, as iniciativas de normatização do direito de o cidadão tomar conhecimento sobre como seus governantes eleitos e os gestores públicos conduzem o patrimônio material e imaterial da nação.

Outro reflexo dessa conjuntura globalizada, o desenvolvimento econômico, aliado ao desenvolvimento das tecnologias da informação e comunicação (TICS), e a demanda para a transparência pública levaram o governo brasileiro, no ano 2000, a lançar o programa Sociedade da Informação com diretrizes para orientar as ações governamentais quanto à aplicação planejada das TICs em diversas áreas de sua atuação.

Esta iniciativa diz respeito às propostas de um grupo qualificado montado pelo então Ministério da Ciência e Tecnologia (MCT) responsável pela implantação do projeto que aborda várias temáticas pertinentes a diretrizes norteadoras para o funcionamento governamental e adaptação da sociedade brasileira frente ao desenvolvimento cada vez mais intenso da sociedade da informação mundial (TAKAHASHI, 2000). Essas diretrizes tratam da caracterização da sociedade da informação, mercado de trabalho, universalização de serviços para a cidadania, educação e cultura, dentro outras, neste contexto histórico.

Dentre estes temas, ressaltamos a seção que trata do governo digital: Governo ao alcance de todos, o governo eletrônico. Barreto Júnior e Rodrigues (2013) afirmam que o governo eletrônico se caracteriza pela mobilização de recursos visando à disponibilização de informações e serviços à sociedade através da rede mundial de computadores. Os autores reforçam que este investimento resulta em uma forma de interação que possibilita maior integração dos processos governamentais em níveis local, regional, nacional e internacional, permitindo a realização eficaz de atividades e serviços públicos, mediante transações eletrônicas com os cidadãos, fornecedores, empresas e outras entidades, de forma a democratizar a atuação estatal, tornando-a mais moderna, eficiente, eficaz e transparente. 0 governo eletrônico é uma realidade consolidada e se aprimora à medida que os fundamentos da sociedade em rede de avançam.

É no contexto da prevalência da virtualidade em praticamente todas as áreas e atividades da humanidade que se pretende discutir a transparência da administração pública no Brasil, mais precisamente, o aspecto da transparência ativa que é o aspecto mais facilmente verificável, uma vez que independe da provocação do cidadão e depende totalmente da consonância das autoridades e gestores públicos com a cultura de publicização de suas atividades e prestação de contas à sociedade.

\subsection{Objetivos e Objetos do Estudo}

Sendo a transparência ativa um tema que possibilita olhares sob diversos prismas e passível de estudo aplicado ao serviço público em toda a sua extensão, mas também de imensa diversidade, escolhemos como recorte analisar os portais eletrônicos na internet das três instituições federais de ensino superior (IFES) no estado da Paraíba que são: o Instituto Federal da Paraíba (IFPB); a Universidade Federal de Campina Grande (UFCG); e a Universidade Federal da Paraíba (UFPB).

Justificamos nossa escolha por estas instituições por serem referenciais para a sociedade paraibana e brasileira em qualidade de ensino superior público, além da demanda por diversos setores da sociedade civil, considerando a amplitude de sua missão social no campo do ensino superior, da pesquisa acadêmica com resultado no desenvolvimento científico regional e nacional e na extensão como a aplicação social de suas atividades. Também consideramos o fato de localizarem-se no mesmo estado do Programa de PósGraduação em Gestão de Organizações Aprendentes (PPGOA) do qual fazemos parte. 
Assim, considerando a demanda por acesso a informações e transparência dos governos e suas entidades na era da sociedade em rede, procuramos responder à seguinte pergunta: Como as instituições federais de ensino superior do estado da Paraíba adequam-se à transparência ativa determinada pela Lei n.o 12.527, de 18 de novembro de 2011, a Lei de Acesso à Informação (LAI)?

Procuramos analisar a transparência ativa determinada pela LAI através dos dispositivos correlatos em seu decreto regulamentador no âmbito do poder executivo federal pelo Decreto n.o 7.724, de 16 de maio de 2012, tendo ainda os seguintes objetivos específicos: Verificar os pontos de transparência ativa elencados na legislação mencionada nos portais das instituições pesquisadas; Avaliar qualitativamente a adequação à transparência ativa dos portais das instituições escolhidas quanto à facilidade de acesso e visibilidade.

Nossa escolha pelo tema se pautou pelo peso que a virtualidade adquiriu e continua adquirindo na atual conjuntura das comunicações planetárias, onde o ciberespaço ocupa um lugar de destaque. Neste cenário, tenciona-se avaliar a relação da administração pública quanto ao cumprimento da legislação existente no que se refere às informações públicas que devem ser publicizadas obrigatoriamente na rede mundial de computadores.

Outrossim, o estudo realizado na dissertação aponta preliminarmente para um desencontro entre a aplicação da transparência ativa de uma IFES e a percepção de seus próprios servidores quanto à transparência da instituição após concluírem curso de capacitação ofertado pela instituição sobre a LAl. Contudo, é preciso ressaltar que a transparência ativa é apenas um dos aspectos que englobam a prática de transparência governamental.

O decreto de regulamentação da LAl apresenta pela primeira vez a expressão "transparência ativa" para se referir às informações que devem ser obrigatoriamente divulgadas pelas entidades governamentais, independentemente de solicitação por parte da sociedade (BRASIL, 2012). Passados nove anos da publicação da lei e oito de seu decreto regulamentador, pela revisão de literatura realizada até o momento, a publicização de informações ainda não é uniforme (se é que deveria sê-lo) para todos os órgãos e para todas as esferas de poder. Portanto, em se tratando de informações que devem ser disponibilizadas principalmente por meio eletrônico, pode-se averiguar o status da aplicação da lei para os órgãos escolhidos.

\subsection{Procedimentos metodológicos}

Nosso estudo se configura em uma revisão de assuntos, exploratória, de abordagem qualitativa e documental. Os procedimentos metodológicos consistiram na leitura crítica de artigos, capítulos de periódicos e livros na plataforma Periódicos da Capes e em outras fontes, a exemplo do guia da Transparência Ativa (GTA) da Controladoria-geral da União (CGU) (BRASIL, 2016). Estas referências tratam do direito do acesso à informação, sociedade da informação e cidadania digital, a partir dos quais procuramos traçar a linha do tempo das discussões em torno do tema, desde o reconhecimento do direito à informação como direito humano fundamental (DUDH, 1948) até recentes publicações com ênfase na transparência ativa (BARRETO JÚNIOR; RODRIGUES, 2013; SILVA; EIRÃO, CAVALCANTE, 2014; BARROS; MEDLEG, 2018).

Alinhamos a este referencial teórico a análise documental da Lei de Acesso à Informação (LAI) e o Decreto 7.724, de 16 de maio de 2012 concentrando-nos no que estabelecem para a transparência ativa. Ressaltamos que outros normativos governamentais também abordam aspectos relativos ao uso da rede mundial de computadores e transparência governamental. São eles: a Lei n.o 12.965, de 23 de abril de 2014, chamada informalmente pela mídia de marco civil de uso da internet e o Decreto $\mathrm{n}$. - 8.777 , de 11 de maio de 2016, que 
versa sobre a política de dados abertos no âmbito do poder executivo federal. Todavia, são mencionados a título de reforço da importância da divulgação de dados em outros formatos para além da transparência ativa.

Para o cumprimento dos nossos objetivos geral e específicos, acessamos os portais eletrônicos das Instituições Federais de Ensino Superior (IFES) da Paraíba no mês de maio de 2020, especificamente sua a seção da transparência ativa. Estas seções se configuraram em nosso corpus. $O$ acesso se deu através do navegador Mozilla Firefox versão 75. Para auxiliar na execução dos objetivos propostos, em consonância com as referências mencionadas anteriormente, elaboramos como instrumento de verificação de informações referentes à transparência ativa das IFES do Estado da Paraíba os quadros 2, 3 e 4, considerando o que dispõe o decreto federal em seus artigos 7ํㅜ e 8o do Capítulo III, intitulado "Da Transparência Ativa".

Além dos dispositivos da LAI e do decreto, consideramos o Guia de Transparência Ativa (GTA) (BRASIL, 2016) que foi elaborado pela CGU com a finalidade de orientar os órgãos do poder executivo federal quanto à divulgação de informações elementares, de maneira obrigatória, voluntária e proativamente, citando a LAl e o decreto regulamentador. Justifica sua existência em virtude da diversidade de informações produzidas ou custodiadas pelo poder público, como forma de auxílio no cumprimento legal (CGU, 2019).

\section{DA DEMANDA SOCIAL POR INFORMAÇÃO AO CIDADÃO: A SUA REGULAMENTAÇÃO NA ERA DA SOCIEDADE DA INFORMAÇÃO}

O grande salto nas sociedades democráticas no que se refere à publicidade dos governos ocorreu após a Segunda Guerra Mundial, concretizado e oficializado com a Declaração Universal dos Direitos Humanos (DUDH) no ano de 1948, três anos após a fundação das Organizações das Nações Unidas (ONU), instituição internacional criada a partir do final do conflito. Seu artigo 19 foi o primeiro de um dispositivo legal de alcance internacional a estabelecer o direito de acesso à informação na era moderna como um direito básico de todo ser humano.

A partir da DUDH, foram organizadas várias convenções e celebrados vários instrumentos internacionais visando respaldar juridicamente o direito de acesso à informação. Segundo Rodrigues (2013), no Brasil, a criação da LAl precedeu um amplo debate de diversos segmentos da sociedade civil organizada e com forte participação da imprensa. Este debate pelo direito à informação surge mais fortemente durante o processo de redemocratização do Brasil, o qual culminou com a promulgação da Constituição Federal (CF) de 1988 (BARROS; MEDLEG, 2018) após 21 anos de restrição das liberdades individuais.

No Quadro 1, relacionamos os principais instrumentos internacionais de referência para os normativos internos brasileiros do direito de acesso à informação (LAl e decreto), todos anteriores à criação da lei brasileira, conforme a Coletânea de Acesso à Informação da Ouvidoria-Geral da União (2016), além dos citados por Rodrigues (2013) e que não configuram no guia, mas que tiveram clara relevância e peso no debate que resultou na LAl e de outros instrumentos internacionais. Vale lembrar também que a criação da LAl é resultado de previsão constitucional. 
Quadro 1 - Instrumentos normativos internacionais sobre acesso à informação

\begin{tabular}{|c|c|}
\hline Normativo & Dispositivo \\
\hline $\begin{array}{l}\text { 1. Declaração Universal dos Direitos } \\
\text { Humanos (1948) }\end{array}$ & $\begin{array}{l}\text { Artigo 19: Estabelece que todo ser humano tem direito a } \\
\text { receber e transmitir informações e ideias por quaisquer } \\
\text { meios e independentemente de fronteiras. }\end{array}$ \\
\hline $\begin{array}{l}\text { 2. Pacto Internacional sobre Direitos } \\
\text { Civis e Políticos (1966) }\end{array}$ & $\begin{array}{l}\text { Artigo 19, parágrafo segundo: Estabelece que toda pessoa } \\
\text { tem direito à liberdade de procurar, receber e difundir } \\
\text { informações e ideias, independentemente de fronteiras e por } \\
\text { qualquer forma ou meio. Seu parágrafo } 3 \text { o fala de } \\
\text { responsabilidades especiais no que se refere às restrições } \\
\text { que devem ser previstas em lei. }\end{array}$ \\
\hline $\begin{array}{l}\text { 3. Convenção Americana sobre } \\
\text { Direitos Humanos ou Pacto de San } \\
\text { José da Costa Rica (1969) }\end{array}$ & $\begin{array}{l}\text { Artigo 13: Replica o artigo } 19 \text { do Pacto Internacional sobre } \\
\text { Direitos Civis e Políticos (1966). Porém, reforça o princípio da } \\
\text { restrição como exceção. }\end{array}$ \\
\hline $\begin{array}{l}\text { 4. Declaração de Princípios sobre } \\
\text { Liberdade de Expressão (2000) }\end{array}$ & $\begin{array}{l}\text { Princípio 4: Afirma que o acesso à informação em poder do } \\
\text { Estado é um direito fundamental do indivíduo, atrelando sua } \\
\text { negação à justificativa excepcional prevista em lei. }\end{array}$ \\
\hline $\begin{array}{l}\text { 5. Convenção das Nações Unidas } \\
\text { Contra a Corrupção (2003) }\end{array}$ & $\begin{array}{l}\text { Artigo 10: Estabelece a necessidade de aumentar a } \\
\text { transparência da administração pública através da } \\
\text { instauração de procedimentos e regulamentações que } \\
\text { concedam ao público acesso a informações da administração } \\
\text { pública. Artigo 13: Estabelece a necessidade de adotar } \\
\text { medidas para fomento da participação da sociedade através } \\
\text { do aumento da transparência pública e garantia do acesso à } \\
\text { informação. }\end{array}$ \\
\hline $\begin{array}{l}\text { 6. Declaração do Rio sobre Meio } \\
\text { Ambiente e Desenvolvimento ECO } \\
92 \text { (Rio de Janeiro, 1992) }\end{array}$ & $\begin{array}{l}\text { Princípio 10: Estabelece que cada indivíduo terá acesso às } \\
\text { informações de que dispõem as autoridades públicas } \\
\text { relativas às questões ambientais. Estabelece ainda que os } \\
\text { estados coloquem as informações à disposição de todos } \\
\text { visando à conscientização popular. }\end{array}$ \\
\hline $\begin{array}{l}\text { 7. Conferência Internacional sobre } \\
\text { Direito à Informação }\end{array}$ & $\begin{array}{l}\text { Detalha as conclusões, princípios e plano de ação resultantes } \\
\text { das discussões da respectiva conferência. Dentre estes } \\
\text { aspectos: ressalta a necessidades de os estados criarem } \\
\text { instrumentos legais para garantir o direito de acesso à } \\
\text { informação, sendo este a regra e colocando o segredo como } \\
\text { exceção prevista em lei. Quanto ao seu plano de ação, prevê } \\
\text { ações específicas para os atores envolvidos: a comunidade } \\
\text { internacional, os estados nacionais e as organizações } \\
\text { corporativas, profissionais e da sociedade civil. }\end{array}$ \\
\hline $\begin{array}{l}\text { 8. Princípios sobre o Direito de } \\
\text { Acesso à Informação do Comitê } \\
\text { Jurídico Interamericano (2008) }\end{array}$ & $\begin{array}{l}\text { Sua resolução traz os princípios norteadores de acesso à } \\
\text { informação como regra, que a responsabilidade por negativas } \\
\text { recaiam aos órgãos, e que toda pessoa que intencionalmente } \\
\text { negue ou obstrua o acesso à informação seja punida } \\
\text { conforme a lei. }\end{array}$ \\
\hline $\begin{array}{l}\text { 9. Convenção do Conselho da Europa } \\
\text { sobre o Acesso aos Documentos } \\
\text { Públicos (2009) }\end{array}$ & $\begin{array}{l}\text { Estabelece no seu artigo } 10 \text { que os documentos públicos } \\
\text { devem ser divulgados pelas autoridades por sua própria } \\
\text { iniciativa a fim de promover transparência, eficiência e } \\
\text { promover participação fundamentada da sociedade. }\end{array}$ \\
\hline
\end{tabular}

Fonte: Elaboração própria a partir de Rodrigues (2013); Ministério da Transparência, Fiscalização e Controladoria-Geral da União (2016); Barros e Medleg (2018)

A leitura dos dispositivos destacados no quadro 1 dos instrumentos internacionais existentes, da LAI e do decreto leva-nos a perceber clara influência daqueles no debate 
nacional em torno da criação da legislação brasileira, pois todos os princípios discutidos internacionalmente podem ser encontrados nela. Concluímos que os instrumentos internacionais convergem nas seguintes prerrogativas quanto ao direito do acesso à informação:

- Criação pelos Estados-partes relativos a cada organismo internacional de mecanismos e regulamentações para salvaguardar o direito de acesso às informações públicas dos governos em seus diversos níveis;

- Conscientização das populações sobre o seu direito à informação pública;

- O acesso à informação como regra e qualquer negação ao seu exercício devem ser restritos e expressamente previstos em lei;

- A publicização pelos governos das informações, quanto às atividades da administração pública de maneira proativa, não deve esperar a provocação da sociedade para que tais informações sejam disponibilizadas rotineiramente.

Importante mencionarmos que conforme consta na Coletânea de Acesso à Informação da Ouvidoria-Geral da União (2016), alguns destes instrumentos normativos foram ratificados pelo governo brasileiro através de decretos, provando o caráter impositivo que estes instrumentos internacionais representam para a salvaguarda do direito à informação e publicidade dos governos.

\subsection{Acesso à informação no Brasil: normativos nacionais}

No contexto regional da América do Sul quanto à positivação do direito de acesso à informação, outros países saíram à frente do Brasil, como Peru (2002), Equador (2004), Uruguai (2008) e Chile (2009) (SILVA; EIRÃO; CAVALCANTE, 2014). De modo geral, percebemos o retardo dos países sul-americanos no tocante à criação da legislação necessária para a implementação da transparência governamental em relação às nações mais avançadas frente às tendências mundiais. Turbulências devidas aos regimes autoritários foram um obstáculo claro neste sentido.

No Brasil, a primeira legislação a tratar do acesso à informação foi a Constituição Federal de 1988, que prevê o acesso à informação nos seguintes dispositivos: inciso XXXIII do art. 5, no inciso II do $\S 30$ do art. 37 e no $\S 20$ do art. 216. Não obstante, interpretações sobre sigilo que fundamentaram algumas negações a informações solicitadas por cidadãos indicavam a necessidade de uma lei única que regrasse o seu acesso (PAES, 2011).

Antes da promulgação desta lei específica que concentra as normas de transparência pública, o cidadão brasileiro poderia ter acesso limitado a uma parte das informações públicas através do acionamento de legislação (decretos, instruções normativas, portarias e leis) dispersa que regulamenta áreas diversas como responsabilidade fiscal, preservação do meio ambiente, guarda de documentos, dentre outros, e que tratava apenas de forma parcial, direta ou indiretamente, a questão do acesso à informação (PAES, 2011; GAMA; RODRIGUES, 2018).

A Lei $n$. o 12.527 foi promulgada em 18 de novembro de 2011 pelo governo federal, na gestão da presidenta Dilma Rousseff, provendo assim o cidadão com instrumento legal específico para salvaguardar seu direito de acesso à informação. Nas suas disposições finais e transitórias, mais especificamente em seu artigo 42, a lei estabelece que o poder executivo regulamente os dispositivos nela contidos em até 180 dias a contar da data de sua publicação. Consequentemente, o Decreto n.o 7.724 que regulamenta a LAI no âmbito federal foi criado em 16 de maio de 2012.

Tanto a LAI quanto o seu decreto estão alinhados aos preceitos dos instrumentos internacionais discutidos acima (positivação do direto à informação, restrição de sigilo, 
proatividade da publicidade). Estes aspectos são considerados norteadores e constituem diretrizes emanadas pela Organização das Nações Unidas (ONU) e pela Organização dos Estados Americanos (OEA) para a criação da legislação que disciplina a transparência em nível nacional (SILVA; EIRÃO; CAVALCANTE, 2014).

Em adição ao texto da LAI, o decreto federal traz os termos transparência ativa e transparência passiva, respectivamente em seus capítulos III e IV, pois apesar de trazer esses dois princípios implícitos, a LAI não utiliza esta nomenclatura. $O$ art. 70 do decreto que trata da transparência ativa estabelece como dever dos órgãos e entidades públicas promover, independentemente de requerimento, a divulgação em seus sítios na internet de informações de interesse coletivo ou geral por eles produzidas ou custodiadas (BRASIL, 2012).

Assim, a transparência ativa é a divulgação obrigatória por força da lei de informações pelo poder público através da rede mundial de computadores. Os artigos 7ํㅜ e 8 o elencam os dados básicos que devem constar nesta seção e que exploraremos mais adiante. Outrossim, cabe-nos ressaltar outro aspecto relativo à divulgação de informações pelos órgãos, a transparência proativa. O Guia da Transparência Ativa (GTA) para os órgãos e entidades do Poder Executivo Federal da Controladoria-Geral da União (CGU) em seu glossário faz distinção entre transparência ativa e proativa. No caso, a transparência proativa é a divulgação de informações pela Administração Pública por iniciativa própria, de forma espontânea, independentemente de qualquer solicitação da sociedade (CGU, 2019).

Sousa, Oliveira e Sousa (2016) afirmam que a transparência ativa é uma tendência e que o poder público, ao promover a disponibilização de tais informações, torna possível o exercício da cidadania, além de economia de tempo e recursos públicos. Para o cidadão, por outro lado, afirmam estes autores que constituem vantagens a redução do tempo de obtenção de respostas e o julgamento da qualidade da informação, se esta lhe é satisfatória ou não.

A transparência passiva, por seu turno, diz respeito a informações públicas não classificadas que não constam das informações mínimas de divulgação obrigatória e/ou que não estão publicadas nos portais eletrônicos públicos, mas que estão sob a guarda dos órgãos públicos e podem ser acessadas, independentemente do suporte do documento físico ou digital, através do requerimento à entidade pública. Os artigos do 9o ao vigésimo quarto do decreto federal estabelecem os critérios e procedimentos mínimos para que qualquer cidadão possa realizar seu pedido junto aos órgãos públicos (BRASIL, 2012). É neste capítulo que se estabelece para todos os órgãos a criação do Serviço de Informação ao Cidadão (SIC), principal canal da transparência passiva.

Além da LAl e de seu decreto, o governo Rousseff também deu mais um passo para a modernização do estado brasileiro na era da sociedade da informação ao propor a Lei n.o 12.965, de 23 de abril de 2014, que estabelece os princípios, direitos, deveres e diretrizes do uso da internet no País, chamada de marco civil da internet. Como consequência, desta lei derivou o Decreto n.o 8.777 que institui a política de dados abertos na esfera federal. Em seu art. 10 encontraremos:

Art. 10 Fica instituída a Política de Dados Abertos do Poder Executivo federal, com os seguintes objetivos:

[...]

II - aprimorar a cultura de transparência pública;

[...]

$\mathrm{V}$ - fomentar o controle social e o desenvolvimento de novas tecnologias destinadas à construção de ambiente de gestão pública participativa e democrática e à melhor oferta de serviços públicos para o cidadão;

[...]

(BRASIL, 2014) 
Destacamos na passagem acima dois termos primordiais para a transparência: cultura da transparência e controle social, reforçando a perspectiva dada às informações públicas e o papel da sociedade frente à publicidade governamental. Deste modo, percebemos que a legislação brasileira busca alinhar-se ao princípio de esclarecer e conscientizar a população quanto ao exercício da cidadania através do conhecimento da gestão do bem público por meio da publicização dessas informações. Assim enfatiza-se a relação direta entre os cidadãos, as instituições e órgãos públicos.

Entretanto, também há retrocessos na atual conjuntura política brasileira, haja vista que o governo Bolsonaro, alçado à presidência do país em 2019, emitiu o Decreto n. 9.690, de 23 de janeiro de 2019, que altera dispositivos do Decreto n.o 7.724/2012. Com o propósito de atualizar a designação dos órgãos responsáveis por determinados dispositivos no documento, a exemplo da troca de Ministério do Planejamento, Orçamento e Gestão por Ministério da Economia, este novo decreto realiza uma mudança importante na atribuição de competência para classificar informações públicas nos graus ultrassecreto e secreto, permitindo a delegação desta competência a agentes de patamares mais baixos.

Esta alteração vai na contramão da tendência do mundo democrático, principalmente se comparada a nações mais avançadas econômica e socialmente, onde gestões governamentais cada vez mais transparentes são defendidas e cobradas pela população. $\mathrm{Na}$ prática, quanto mais extensa a lista de cargos e funções com esta capacidade legal, mais vulnerável às vontades dos agentes públicos as informações estarão. Em outras palavras, aumenta o número de exceções, ao passo que os normativos discutidos anteriormente prescrevem a publicização como a regra.

Em decorrência da repercussão negativa ${ }^{1}$, os dispositivos referentes à ampliação do rol de autoridades com poder de restringir o acesso a informações foram revogados pelo Decreto n. .9 .716 , de 26 de fevereiro de 2019, demonstrando o poder do controle social em uma sociedade democrática.

\section{CONTROLE SOCIAL E CIDADANIA DIGITAL}

Nas sociedades democráticas modernas, a demanda por acesso à informação e transparência tem sido reforçada à medida que essas sociedades se tornam cada vez mais dependentes das atividades produtivas baseadas nas modernas TICs com repercussão na vida social. A sociedade da informação configura-se como reflexo do atual estágio de desenvolvimento da ciência da informação que possibilitou à sociedade moderna permanecer conectada através da rede mundial de computadores, a internet, com praticamente acesso a todo tipo de serviço e informação do planeta (FERREIRA, 2014). E:

Questões como a da circulação da informação e do conhecimento, processo esse de dimensões política, econômica, social e cultural, cada vez mais mediado pelas redes digitais, cujo acesso é facilitado sobretudo pelo barateamento de tecnologias como microcomputadores e, mas (sic) recentemente, tablets e smartphones, viabilizando, desse modo, a comunicação e a sociabilidade remota entre pessoas. (FERREIRA, 2014, p. 114)

Contudo, Ferreira (2014) analisa a questão da sociedade de controle versus a sociedade da informação a partir do ponto de vista do controle pelo cidadão daqueles que detêm o poder político e econômico, os governos. Entendendo que o desenvolvimento do

1 Vide a URL: https://www.transparencia.org.br/blog/nota-sobre-o-decreto-n-9-6902019-quealtera-regras-de-classificacao-de-informacao/ . Acesso em: 2 out. 2019. 
ciberespaço possibilita a esses mesmos governos acesso a informações das mais diversas e detalhadas sobre os indivíduos inseridos na sociedade, é pertinente afirmar que, considerando a diversificação e ampliação de acesso ao ciberespaço via dispositivos móveis, e considerando ainda a criação de mecanismos e legislações que obriguem os governos a serem mais transparentes, o controle social na sociedade da informação se torna uma via de mão dupla. 0 cidadão que é vigiado pelos sistemas de informação governamentais também detém a prerrogativa de exigir do poder público transparência como ferramenta de controle social, o que nos obriga a pensar no conceito de cidadania digital, que será explorado mais adiante.

Ampliando a reflexão sobre o controle social, Lévy (2000) chama a atenção sobre as práticas democráticas eletrônicas, quando afirma que essas práticas não devem ser confundidas com ações simples como propagandas governamentais sobre a rede ou a disponibilização de endereços eletrônicos, que não contribuem para gerar transformações nas relações entre as autoridades e os cidadãos. A verdadeira prática democrática diz respeito à utilização das ferramentas de comunicação digital para um constante levantamento de problemas das comunidades através da participação cidadã das populações afetadas pelas decisões dos governantes, através da transparência de políticas públicas e da avaliação dessas pela comunidade interessada diretamente (LÉVY, 2000).

Desse modo, o direito de acesso à informação e a conscientização da sociedade quanto a este direito e disseminação na esfera pública da cultura da transparência são apenas aspectos, dos mais imprescindíveis, da democracia eletrônica na sociedade da informação, que demanda ações cidadãs ativas.

Assim, é preciso refletir sobre a cidadania nesta nova era. A cidadania configura-se em um processo em constante construção atrelado ao surgimento pelos direitos civis ainda no século XVIII e representa um conjunto de direitos que possibilitam ao indivíduo participar de maneira ativa do governo de um país, ficando à margem da vida social e da tomada de decisões dos que não a têm (DALLARI, 1998 apud TEIXEIRA; REIS, 2013).

As autoras ponderam também que a cidadania se tornou referencial da luta pelos direitos humanos e que o ser cidadão é "ter consciência da sua condição de sujeito de direitos civis, políticos e sociais e também de deveres e responsabilidades como parte integrante da coletividade" (TEIXEIRA; REIS, 2013, p. 208). Neste artigo, as autoras ampliam a discussão para a questão da cidadania, sob o ponto de vista da guarda da informação sobre o patrimônio cultural imaterial e a cidadania digital, que encontra um ponto em comum sobre nosso olhar no presente trabalho. Tratando da importância de programas governamentais, educacionais e inclusivos que promovam a participação de toda a comunidade quanto à conscientização sobre o patrimônio cultural, dizem:

Neste sentido, com ênfase na transmissão da informação, para além de uma cidadania cultural, pressupõe-se também uma cidadania digital, entendendo o termo cidadania digital como a utilização dos recursos digitais para a promoção do acesso à informação e como elemento facilitador para o exercício dos direitos e deveres de cada indivíduo perante o Estado. Partimos do pressuposto de que a importância de se propagar o exercício de uma cidadania digital se amplia na medida em que as informações circulam em tempo real e que os sujeitos ao acessá-la e atribuir-lhe significado podem articular processos de mudança e transformação. (TEIXEIRA; REIS, 2013, p. 209-210)

Sobre a perspectiva de governo eletrônico, Barreto Júnior e Rodrigues (2013) estudam a influência das novas tecnologias da informação e comunicação frente à gestão administrativa, ressaltando que um governo baseado na modernização tecnológica amplia as 
possibilidades para a participação do cidadão nas tomadas de decisão, forçando o Estado a assumir um novo perfil, mais aberto à prestação de contas para a sociedade, enfatizando assim a transparência e o controle social. Além disso, com a diminuição de procedimentos burocráticos através da oferta de muitos serviços online, o governo também tem de promover a democratização dos meios de acesso eletrônico, com vistas a diminuir a exclusão social e fomentar a cidadania de fato na nova era.

\section{TRANSPARÊNCIA ATIVA E CIDADANIA DIGITAL: NAVEGANDO NOS PORTAIS DAS IFES DA PARAÍBA}

Passamos, pois, a verificar a transparência ativa nos portais das IFES selecionadas (IFPB. UFCG e UFPB) com vistas a atingir os objetivos propostos de acordo com a os procedimentos metodológicos explicados na seção 1.3.

O decreto determina que deve ser implementada seção específica nos portais eletrônicos dos órgãos e entidades para divulgação das informações da transparência ativa. No preenchimento dos quadros, marcamos SIM para a existência da seção específica nos portais eletrônicos das IFES com o conteúdo da respectiva informação conforme o dispositivo do decreto; PARCIAL para a existência da seção, porém, sem o conteúdo da informação específica, ou esta informação está incompleta; e NÃO para a inexistência da seção específica.

0 quadro 2 traz as informações sobre o layout inicial dos portais, especificamente o que determina 0 art. 70 do Decreto $n .0$ 7.724/2012 que trata de links que facilitam a identificação da esfera governamental e da divulgação do portal da transparência de cada entidade ou órgão.

Navegando pelos portais, verificamos que apenas a UFCG não apresenta um banner único que concentre todas as informações elencadas para a transparência ativa em um só local. Para esta universidade, há o banner Transparência que remete à página da instituição dentro do Portal da Transparência nacional com informações sobre execução orçamentária e financeira. Em outro local da página inicial, existe também a seção Acesso à Informação que traz subseções determinadas pelo decreto, mas não todas as elencadas no $\S 3$ o do art. 7으, que estão detalhadas no quadro 2.

Quadro 2 - Verificação da transparência ativa das IFES da Paraíba de acordo com o § 2ㅇ do Art. 70 do Decreto n.o 7.724/2012

\begin{tabular}{|l|c|c|c|}
\hline Inciso: & IFPB & UFCG & UFPB \\
\hline $\begin{array}{l}\text { I - banner de acesso a informações de interesse } \\
\text { coletivo ou geral na página inicial }\end{array}$ & SIM & NÃO & SIM \\
\hline $\begin{array}{l}\text { II - barra de identidade do Governo Federal, } \\
\text { com ferramenta de redirecionamento de } \\
\text { página para o Portal Brasil e para o sítio } \\
\text { principal sobre a Lei n.o 12.527, de 2011 }\end{array}$ & SIM & SIM & SIM \\
\hline
\end{tabular}

Fonte: Elaboração própria a partir do Decreto Federal n. 7.724/2012

No inciso I do art. 70 (Quadro 2) é detalhado que o decreto elenca no seu $\S 3$ deste artigo, ou seja, este dispositivo detalha as informações de interesse geral e coletivo que devem constar em seção específica. Para analisar sua presença nos portais das IFES, organizamos o Quadro 3: 
Quadro 3 - Transparência ativa das IFES públicas federais da Paraíba de acordo com o § 3ㅇ do Art. 7o do Decreto n. $7.724 / 2012$

\begin{tabular}{|c|c|c|c|}
\hline Inciso: & IFPB & UFCG & UFPB \\
\hline $\begin{array}{l}\text { I - estrutura organizacional, competências, } \\
\text { legislação aplicável, principais cargos e seus } \\
\text { ocupantes, endereço e telefones das unidades, } \\
\text { horários de atendimento ao público } \\
\text { (Institucional) }\end{array}$ & SIM & NÃO & SIM \\
\hline $\begin{array}{l}\text { II - programas, projetos, ações, obras e } \\
\text { atividades } \\
\text { (Ações e programas) }\end{array}$ & PARCIAL & NÃO & SIM \\
\hline $\begin{array}{l}\text { III - repasses ou transferências de recursos } \\
\text { financeiros } \\
\text { (Convênios e transferências) }\end{array}$ & PARCIAL & SIM & SIM \\
\hline $\begin{array}{l}\text { IV - execução orçamentária e financeira } \\
\text { detalhada } \\
\text { (Receitas e despesas) }\end{array}$ & SIM & SIM & SIM \\
\hline $\begin{array}{l}\text { V - licitações realizadas e em andamento } \\
\text { (Licitações e contratos) }\end{array}$ & SIM & SIM & SIM \\
\hline $\begin{array}{l}\text { VI - remuneração e subsídio recebidos por } \\
\text { ocupante de cargo, posto, graduação, função e } \\
\text { emprego público } \\
\text { (Servidores) }\end{array}$ & PARCIAL & SIM & SIM \\
\hline $\begin{array}{l}\text { VII - respostas a perguntas mais frequentes da } \\
\text { sociedade } \\
\text { (Perguntas frequentes) }\end{array}$ & PARCIAL & NÃO & SIM \\
\hline $\begin{array}{l}\text { VIII - contato da autoridade de monitoramento } \\
\text { e telefone e correio eletrônico do Serviço de } \\
\text { Informações ao Cidadão - SIC } \\
\text { (Serviço de Informação ao Cidadão - SIC) }\end{array}$ & SIM & NÃO & SIM \\
\hline $\begin{array}{l}\text { IX - programas financiados pelo Fundo de } \\
\text { Amparo ao Trabalhador - FAT }\end{array}$ & NÃO & NÃO & $\mathrm{NA} \mathrm{O}^{2}$ \\
\hline
\end{tabular}

Fonte: Elaboração própria a partir do Decreto Federal n. 7.724, 2012

O Quadro 4 elenca os requisitos que devem atender aos portais das IFES quanto à compatibilidade de formatos e de sistemas, bem como de verificação da autenticidade das informações.

De acordo com o nosso objetivo geral, analisamos a transparência ativa à luz dos instrumentos legais já mencionados, nos portais das instituições federais de ensino superior (IFES) do estado da Paraíba.

Como preconizam as normas legais, o portal de acesso à informação das IFES, independentemente do nome que os gestores responsáveis pela transparência ativa escolheram utilizar para o banner ou seção (como Portal da Transparência, ou apenas Transparência, ou ainda Acesso à Informação, que, neste caso. Pode ser remetido em um segundo nível para o portal de acesso à informação do Governo Federal), de modo geral, procura se adequar ao cumprimento deste quesito. Existe link nos portais eletrônicos, de

2 Na seção “Ações e programas” há a informação de que a UFPB não desenvolve programas do FAT. 
modo que o cidadão encontre facilmente o caminho inicial para a localização da seção de transparência. O Decreto n. 0 7.724/2012, em seu inciso I do parágrafo 20 do art. 70, determina que tal seção deve constar como banner na página inicial. Porém, a UFPB apresenta a opção Acesso à Informação na coluna à esquerda. A UFCG, por outro lado, apresenta tanto no banner no topo da página inicial quanto no menu esquerdo ao fundo, mas os dois links levam a informações de transparência diferentes.

Observamos ao acessar a seção de transparência dos portais das IFES pesquisadas, que há uma preferência pelo layout padronizado das seções segundo as sugestões do GTA da CGU. Por outro lado, uma análise qualitativa mais cuidadosa revela que a seção de transparência das universidades pesquisadas, em termos de informação constante em cada link, não é uniforme à legislação e que muitas das informações elencadas nela estão localizadas de maneira dispersa ao longo das outras seções do portal eletrônico da instituição, como por exemplo, nos casos do IFPB e da UFCG. No sítio eletrônico do IFPB, há a subseção "Convênios e transferências" que não apresenta nenhuma informação ao acessarmos.

Se tomarmos a quantidade de SIM que cada IFES recebeu nos quadros 2, 3 e 4 como sendo o balizador principal de adequação à legislação da transparência ativa, teremos a seguinte ordem decrescente, em termos de adequação ao que estabelece o Decreto n.․ 7724/2012: UFPB, IFPB e UFCG.

O nosso primeiro objetivo específico foi definir os níveis de adequação à transparência ativa dos portais da IFES escolhidas. Navegando no portal da transparência do IFPB, percebe-se que a transparência ativa está funcionando relativamente bem. A instituição apresenta informações atualizadas e faz uso de vários recursos prescritos nos normativos. Apesar de organizar suas informações de acordo com a sugestão contida no GTA da CGU, algumas seções, embora presentes, não contêm informação, mas é possível encontrá-la no módulo que remete aos sistemas internos Figura 1 ) que detêm a informação, a exemplo da seção "Ações e programas". Contudo, não há texto que alerta o cidadão para este direcionamento, o que pode resultar maior esforço para o cidadão localizar a informação.

Figura 1 - Portal da transparência do IFPB

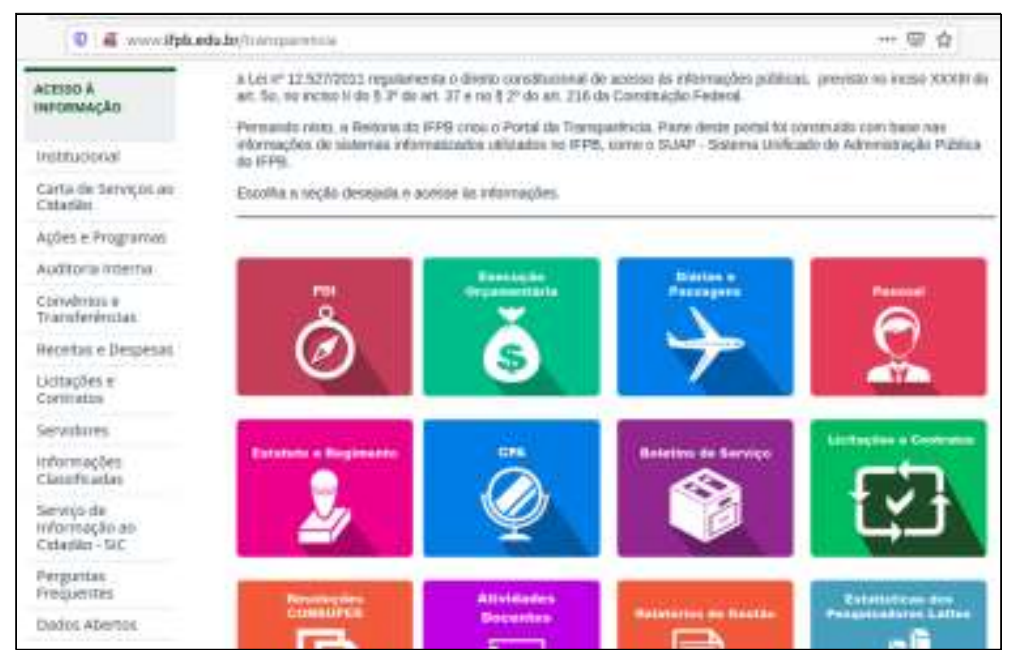

Fonte: http://www.ifpb.edu.br/transparencia. Acesso em: 10 mai. 2020

A UFCG, por outro lado, apresenta sua transparência ativa dispersa, escolhendo não seguir à risca a sugestão constante no GTA da CGU, apesar de a percepção de layout do portal utilizar o padrão do Governo Federal. O portal da instituição possui, em sua página inicial, o banner Transparência no canto superior e o menu Acesso à Informação ao lado direito no 
fundo da página, como mostra a Figura 1. O banner Transparência remete ao Portal da Transparência do Governo Federal especificamente aos dados da UFCG no tocante à execução financeira e orçamentária e informação de pessoal. Este artifício de direcionamento está previsto no $\S 4$ do artigo 7ㅇ do Decreto n. 7.724/2012. Porém, há que se ter claro que nem todas as informações da transparência ativa estarão em outros sítios por serem próprias de cada instituição. A seção nominada Acesso à Informação da UFCG não concentra todas as informações determinadas para a transparência ativa no decreto federal (Figura 2).

Figura 2 - Portal da transparência da UFCG

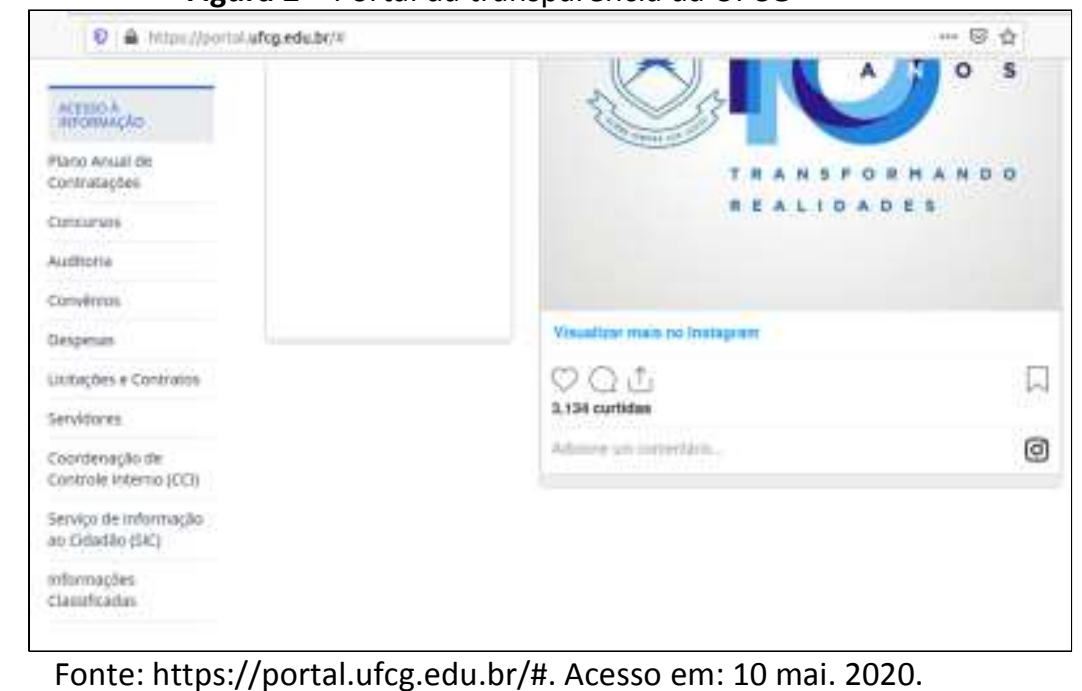

A UFPB, por outro lado, segue exatamente as sugestões constantes no GTA ao disponibilizar as informações de interesse geral em seu portal de transparência. Todas as seções correspondem aos dispositivos da transparência ativa elencados no decreto com exceção à informação referente ao inciso $X$ do art. 70 (programas financiados pelo Fundo de Amparo ao Trabalhador - FAT) que não dispõe de uma seção para si, mas está inserida na subseção Ações e programas.

Dentre as IFES pesquisadas, é a que apresenta a transparência ativa mais completa, com as informações de interesse geral do decreto concentrada em um único portal, inclusive provendo o cidadão com orientações nas próprias seções sempre que a localização de determinada informação pelo cidadão possa lhe demandar um pouco de esforço ou quando é necessário entrar com dados específicos como códigos relativos à identificação da instituição e ações de programas nos sistemas do Governo Federal, como no exemplo da Figura 3. 
Figura 3 - Portal da transparência da UFPB - Subseção Receitas e Despesas.

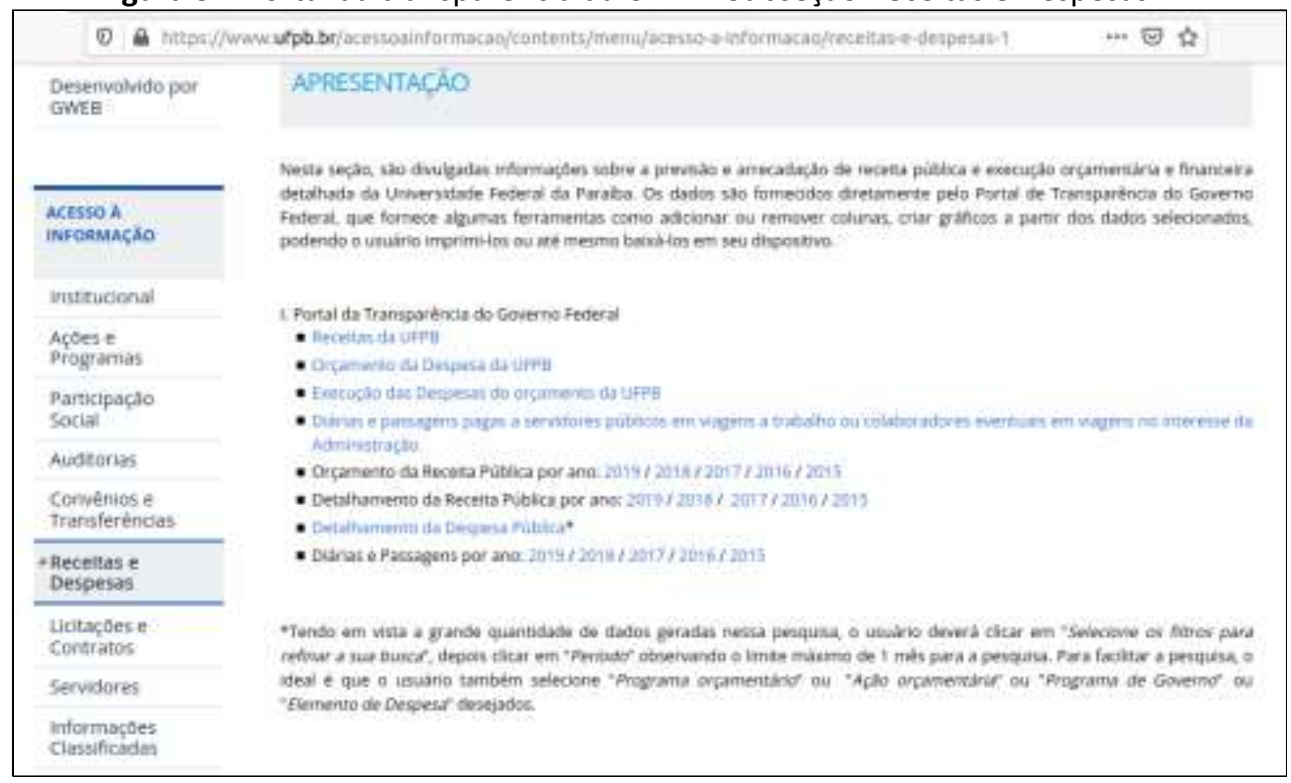

Fonte: https://www.ufpb.br/acessoainformacao/contents/menu/ acesso-a-informacao/receitas-e-despesas-1. Acesso em: 10 mai. 2020.

Quanto às falhas que são comuns a todas as IFES, podemos mencionar a limitação da acessibilidade aos deficientes visuais, pois não localizamos ferramenta de leitura de conteúdo. A acessibilidade visual mais comum é o alto contraste de exibição. Para os deficientes auditivos (surdos), na plataforma do Governo Federal que hospeda os portais eletrônicos das IFES, encontra-se disponível a tradução em Língua Brasileira de Sinais (Libras) através de um avatar.

Tecnicamente, as plataformas que o poder executivo federal tem utilizado para seus portais eletrônicos são da Plone, organização americana de desenvolvimento de plataformas em código aberto, que, ao detectar o equipamento utilizado pelo usuário, adapta o portal eletrônico automaticamente para o modo móvel.

\section{CONSIDERAÇÕES FINAIS}

Em virtude de sua complexidade e capilaridade organizacional, o poder público produz e é guardião de uma infinidade de informações de domínio público que apontam para a qualidade da gestão pública por seus agentes e suas tomadas de decisão e que, por isso, devem estar à disposição do cidadão para que este possa julgar se as ações estão de acordo com o interesse público.

A obrigatoriedade de prestar contas exige de cada entidade, órgão e cada gestor público assumirem não apenas a responsabilidade legal como também o compromisso social de publicização da informação cuja dona em último caso é a sociedade, visto que o estado existe para cuidar do bem de todos. $\mathrm{Na}$ era da sociedade da informação, onde são protagonistas as modernas ferramentas de tecnologia da informação e comunicação e a infraestrutura que suporta o ciberespaço, a transparência governamental possui condições férteis para aprimoramento constante.

Por meio do presente estudo, verificamos que as IFES no estado da Paraíba apresentam interesse em prestar contas à sociedade com a manutenção e publicização de informações gerais mínimas elencadas na forma da lei sobre transparência ativa. Apesar de não haver um padrão estabelecido dos normativos de como essas informações devem estar dispostas nos portais eletrônicos, as IFES acolheram as sugestões constantes no guia da CGU. 
Nos casos em que essas orientações não são seguidas, o cidadão ainda é capaz de localizá-las, ainda que a nomenclatura adotada para algumas seções seja divergente da constante na legislação. Podemos considerar este fato compreensível, pois a LAl determina que a informação seja disponibilizada o mais próximo possível em linguagem acessível a todos.

A partir da LAI, deduzimos que outras informações que merecem destaque na transparência ativa, não configuram no capítulo correlato do Decreto n.o 7.724/2012, mas que é possível encontrar links nos portais das IFES, como as informações sobre auditorias, dados abertos e informações classificadas. Como nosso recorte foi o capítulo específico do decreto, estudos futuros poderão abordar estes e outros aspectos da transparência, além da repercussão de normativos editados que visam restringir o direto irrestrito a informações públicas, a exemplo do Decreto n. 9.690, de 23 de janeiro de 2019.

A divulgação dos dados abertos pelas instituições configura-se em outro patamar de transparência, pois a política de dados abertos possibilita que cada instituição adote seu próprio normativo para disponibilização dos dados, obviamente, assim como as informações classificadas exigem uma seleção mais apurada, sendo a política de dados abertos regulamentada por seu decreto específico.

Finalmente, os resultados preliminares que deram origem a este artigo apontam para a discrepância entre a transparência ativa e a percepção de servidores quanto à transparência geral de uma das IFES pesquisadas, o que nos leva a concluir que a conscientização e a divulgação da transparência, dentro da própria instituição, necessitam ser alvo de investimento por parte do poder público, pois a legislação já prevê esta ação como fundamental e indispensável para reforçar a cultura de transparência.

\section{REFERÊNCIAS}

BARRETO JÚNIOR, I.; RODRIGUES, C. B. Governo eletrônico, cidadania e inclusão digital. Revista Direito e Justiça, n. 01, v.12, n. 19, p. 91-112, mar. 2013. DOI: http://dx.doi.org/10.31512/rdj.v12i19.977 $\quad$ Disponível em: http://srvapp2s.santoangelo.uri.br/seer/index.php/direito e justica/article/view/977/461.

Acesso em: 23 jan. 2019

BARROS, D.S.; MEDLEG, G.R. Acesso à Informação na Região Nordeste: balanço da criação da LAI nos estados e o processo de sua regulamentação no Maranhão. Perspectivas em Ciência da Informação, v. 23, n. 1, p. 2-18. jan./abr. 2018. Disponível em: http://www.scielo.br/scielo.php?script=sci arttext\&pid=S1413-

99362018000100002\&lng=en\&nrm=iso\&tlng=pt. Acesso em: $11 \mathrm{dez} .2018$.

BRASIL. Ministério da Transparência, Fiscalização e Controladoria-Geral da União. OuvidoriaGeral da União. Coletânea de Acesso à Informação. 3. ed. Brasília: 2016.

BRASIL. Ministério da Transparência, Fiscalização e Controladoria-Geral da União. Guia de Transparência Ativa (GTA) para os órgãos e entidades do Poder Executivo Federal. Brasília: 2019. 6a Versão (2019). Disponível em: https://www.gov.br/acessoainformacao/pt-br/lai-parasic/guias-e-orientacoes/gta-6a-versao-2019.pdf . Acesso em: 19 fev. 2020.

BRASIL. Decreto n. 7.724, de 16 de maio de 2012. Regulamenta a Lei no 12.527, de 18 de novembro de 2011, que dispõe sobre o acesso a informações previsto no inciso XXXIII do caput do art. 5o, no inciso II do § 30 do art. 37 e no § 20 do art. 216 da Constituição. Disponível em: 
http://www.planalto.gov.br/ccivil 03/ ato2011-2014/2012/Decreto/D7724.htm. Acesso em: 8 mar. 2018.

BRASIL. Decreto n. 9.690, de 23 de janeiro de 2019. Altera o Decreto no 7.724, de 16 de maio de 2012, que regulamenta a Lei no 12.527, de 18 de novembro de 2011 - Lei de Acesso à Informação. Disponível em: http://www.planalto.gov.br/ccivil_03/_Ato20192022/2019/Decreto/D9690.htm. Acesso em: 24 jan. 2019.

BRASIL. Decreto n. 9.716, de 26 de fevereiro de 2019. Revoga dispositivos do Decreto $\mathrm{n}$ 9.690, de 23 de janeiro de 2019, que altera o Decreto no 7.724, de 16 de maio de 2012, que regulamenta a Lei no 12.527, de 18 de novembro de 2011 - Lei de Acesso à Informação. Disponivel em: $\quad$ http://www.planalto.gov.br/ccivil 03/Ato20192022/2019/Decreto/D9716.htm\#art1 . Acesso em: 15 mai. 2020.

BRASIL. Lei n. 12.527, de 18 de novembro de 2011. Regula o acesso a informações previsto no inciso XXXIII do art. 5o, no inciso II do § 30 do art. 37 e no § 20 do art. 216 da Constituição Federal; altera a Lei no 8.112, de 11 de dezembro de 1990; revoga a Lei no 11.111, de 5 de maio de 2005, e dispositivos da Lei no 8.159, de 8 de janeiro de 1991; e dá outras providências. Disponível em: http://www.planalto.gov.br/ccivil 03/ ato2011-2014/2011/lei/l12527.htm. Acesso em: 23 Ago. 2017.

CONVENTION du Conseil de l'Europe sur l'accès aux documents publics, Troms $\varnothing$, 18.VI.2009. Disponível em: http://conventions.coe.int/Treaty/FR/Treaties/Html/205.htm. Acesso em: 9 dez. 2018.

DECLARATION and Plan of Action for the Advancement of the Right of Access to Information). Disponível em: http://www.cartercenter.org/documents/Atlanta\%20Declaration\%20and\%20Plan\%20of\%20Ac tion.pdf. Acesso em: 19 nov. 2018.

GAMA, J. R.; RODRIGUES, G. M. Transparência e acesso à informação: um estudo da demanda por informações contábeis nas universidades federais brasileiras. TransInformação, Campinas, v. 28, n. 1 , p. 47-57, jan./abr. 2016. Disponível em: http://www.scielo.br/scielo.php?script=sci arttext\&pid=S010337862016000100047\&lng=pt\&tlng=pt. Acesso em: 22 set. 2018.

FERREIRA, Rubens da Silva. A sociedade da informação como sociedade de disciplina, vigilância e controle. Información, cultura y sociedad, Buenos Aires, n.o 31, dez. 2014. Disponível em: http://www.scielo.org.ar/pdf/ics/n31/n31a07.pdf. Acesso em: 03 ago. 2018.

IANNI, O. Teorias da globalização. Rio de Janeiro: 2001. Cap. 1, p. 13-15; cap. 6, p. 118-141.

LÉVY, P. Cibercultura. São Paulo: Ed. 34, 2000. Cap.13, p. 31-44; cap. 13, p. 185-196.

ONU. Declaração Universal dos Direitos Humanos. Organização das Nações Unidas. Disponível em: https://nacoesunidas.org/wp-content/uploads/2018/10/DUDH.pdf. Acesso em: $13 \mathrm{dez}$. 2018. 
RODRIGUES, G. M. Indicadores de "transparência ativa" em instituições públicas: análise dos portais de universidades públicas federais. Liinc em Revista, v. 9, n. 2. p. 423-438, dez. 2013. Disponível em: http://revista.ibict.br/liinc/article/view/3474 . Acesso em: 17 nov. 2018.

SILVA, T. E. da; EIRÃO, T. G.; CAVALCANTE, R. da S. Relacionando la legislación sobre acceso a la Información de los países del MERCOSUR. Biblios Online. n. 56, 2014 Disponível em: https://biblios.pitt.edu/ojs/index.php/biblios/article/view/190. Acesso em: 18 nov. 2019.

SOUSA, R. P. M. de; OLIVEIRA, B. M. J. F. de; SOUSA, M. R. F. de. Reflexões sobre a regulamentação da Lei de Acesso à Informação no âmbito do poder executivo federal. Revista Analisando em Ciência da Informação - RACln. v. 4, n. 2, jul./dez. 2016. Disponível em: http://racin.arquivologiauepb.com.br/edicoes/v4 n2/racin v4 n2 artigo05.pdf. Acesso em: 12 out. 2018.

TAKAHASHI, T. (Org.). Sociedade da informação no Brasil: Livro Verde. Brasília: Ministério da Ciência e da Tecnologia, 2000. Cap.6, p. 68-80.

TEIXEIRA, C. A.; REIS, A. S. dos. Informação e patrimônio cultural imaterial: uma proposta de cidadania digital. Eptic online: revista eletrônica internacional de economia política da informação, da comunicação e da cultura, v.15, n. 2, p. 200-215, maio/ago. 2013. Disponível em: https://seer.ufs.br/index.php/eptic/article/view/949/821. Acesso em: 22 jan. 2019.

Artigo recebido em 04/10/2020 e aceito para publicação em 10/12/2020 